Buenos Aires-Moscú. El partido comunista argentino y la Revolución Rusa hasta los años treinta.

Hernán Camarero

Anuario № 29 / ISSN 1853-8835 / pp. 108-135 /2017

http://anuariodehistoria.unr.edu.ar/ojs/index.php/Anuario/index

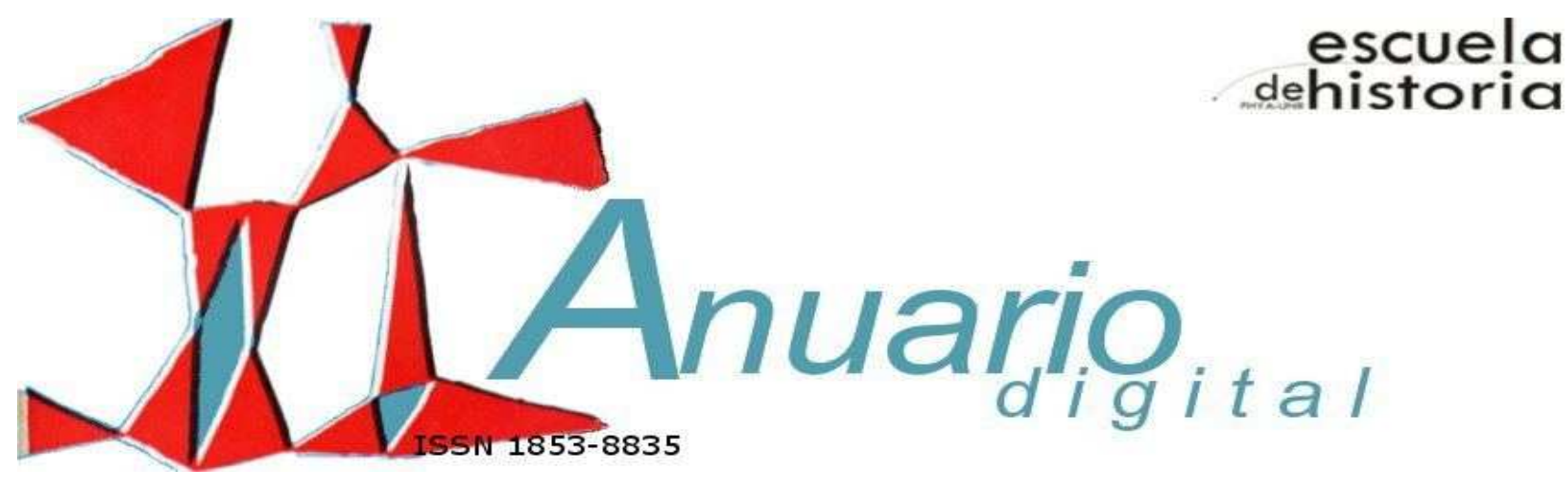

Buenos Aires-Moscú. El Partido Comunista argentino y la Revolución Rusa hasta los años treinta

Buenos Aires- Moscú. The Argentine Communist Party and the Russian Revolution until the 1930s

HERNÁN CAMARERO*

(Universidad de Buenos Aires - Consejo Nacional de Investigaciones

Científicas y Técnicas); Argentina

hercamarero@gmail.com

RESUMEN

La solidaridad con la revolución rusa y las relaciones con la Unión Soviética movilizaron millones de voluntades en todo el mundo. Los comunistas de la Argentina no fueron una excepción. El objetivo de este artículo es el de contribuir al análisis de aspectos de este fenómeno. Se exploran los modos en los que el Partido Comunista tejió vínculos (con el Estado soviético y con la Comintern), desplegó actos de propaganda y expresó un apoyo activo hacia esta causa desde 1917 y hasta comienzos de los treinta, alcanzando algunas conclusiones acerca de las características y la dinámica de dicha fuerza política

Palabras clave: Comunismo argentino; Unión Soviética; Solidaridad; Propaganda; Década del 1930

\footnotetext{
* Doctor en Historia, Universidad de Buenos Aires (UBA). Profesor Asociado-Titular Facultad de Filosofía y Letras (UBA) e Investigador Independiente del CONICET.

Esta obra está sujeta a la Licencia Reconocimiento-NoComercial-Compartirlgual 4.0 Internacional de Creative Commons. http://creativecommons.org/licenses/by-nc-sa/4.0/ 
The solidarity with the Russian Revolution and the Soviet Union mobilized millions of minds worldwide. The Communists of Argentina were no exception. The aim of this paper is to reconstruct this issue. The ways in which the Communist Party had links deployed acts of propaganda and expressed active support to this cause during the twenties and thirties are explored. The purpose is to draw conclusions about the characteristics and dynamics of this political force.

Keywords: Argentine communism; Soviet Union; Solidarity; Propaganda; Decade of 1930's

Transcurre la década de 1920 en la Argentina. Un tango alcanza cierta popularidad, especialmente en la ciudad de Buenos Aires. Elaborado por destacados referentes de esta expresión musical, Mario Battistella, Manuel Romero y Enrique Delfino, se titula "Se viene la maroma". Como la mayoría de los temas de este género, se muestra repleto de frases y palabras propias del "lunfardo" y de otras formas del habla popular de la urbe porteña. Dice su letra:

Cachorro de bacán, / andá achicando el tren, / los ricos hoy están / al borde del sartén. / El vento del cobán, / el auto y la mansión, / bien pronto rajarán / por un escotillón. / Parece que está lista y ha rumbiao / la bronca comunista pa' este lao. / Tendrás que laburar pa' morfar... / iLo que te van a gozar! / Pedazo de haragán, / bacán sin profesión, / bien pronto te verán / chivudo y sin colchón. / Ya está, llegó, no hay más que hablar. / Se viene la maroma sovietista. / Los orres ya están hartos de morfar salame y pan, / y hoy quieren morfar ostras con sauternes y champán. / Aquí ni Dios se va a piantar / el día del reparto a la romana, / y hasta tendrás que entregar a tu hermana / para la comunidad...

El tango no hacía más que traducir un motivo colectivo y, en buena medida, revelaba el impacto generado por la Revolución rusa y el comunismo en el país. Es que el proceso de 1917 concitó la admiración y el apoyo ferviente en algunos o el temor y el odio en muchos otros, pero a ningún individuo interesado 109

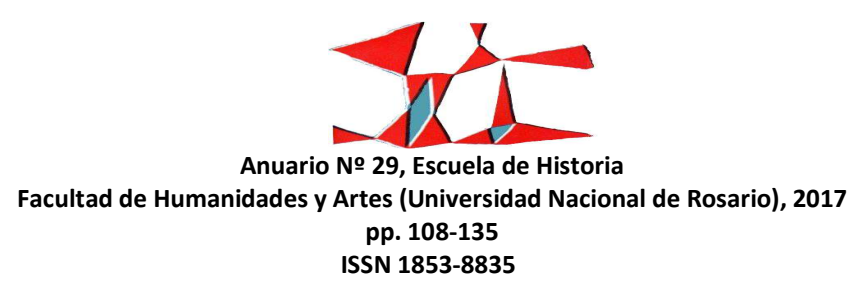


por la realidad social y política de la Argentina le despertó indiferencia. El rechazo al movimiento iniciado en Petrogrado y Moscú comenzó rápidamente y se extendió a lo largo de muchos años con particular virulencia. Los conservadores, la Iglesia, las entidades patronales, la prensa tradicional y, sobre todo, el variopinto espacio del nacionalismo reaccionario, xenófobo y, en ciertos niveles, antisemita, tomó la iniciativa para denunciar el peligro maximalista en Rusia y, por proyección, en las calles obreras, izquierdistas y judías de Buenos Aires y otras ciudades. Denunciaron y atacaron manifestaciones, reuniones, locales y, sobre todo, las combativas huelgas entre 1917-1922, en especial, durante la llamada Semana Trágica. La Liga Patriótica Argentina y la Asociación Nacional del Trabajo quisieron colocarse en la primera línea del combate a la mentada revolución comunista. A fines de los años veinte y en los treinta surgieron nuevas entidades anticomunistas, que impugnaban el sentido de la Revolución dirigida por los bolcheviques.

Si para la clase dominante, las derechas y la prensa dominante, la Revolución de octubre fue una suerte de hecho aberrante, un golpe de estado subversivo y proalemán, y luego un laboratorio social y político preocupante, un eco distinto hubo en otros sectores. Dicha resonancia fue sintonizando con cierta mirada popular, probablemente mayoritaria en el movimiento obrero, pero que también se fue expresando en algunos ámbitos de la vanguardia cultural e intelectual. Emergieron fracciones de simpatía y apoyo entre socialistas, anarquistas y sindicalistas revolucionarios, e incluso en corrientes que iban más allá de las tradicionales expresiones del movimiento obrero y las izquierdas. Pero fue la aparición del comunismo como nueva cultura e identidad política en todo el mundo uno de los grandes resultados de la revolución, y ello ocurrió de un modo rápido y arrollador. Afirmó Hobsbawm: "La revolución de octubre originó el movimiento revolucionario de mayor alcance que ha conocido la historia moderna. Su expansión mundial no tiene parangón desde las conquistas del islam en su primer siglo de existencia". ${ }^{1}$ Incuso, un historiador alemán contrario al marxismo concedía: "tiene fundamento la tesis que considera al comunismo bolchevique como la fuerza política más determinante y singular que jamás haya visto la luz hasta el siglo XX" ${ }^{2}$ Para los comunistas, 1917 fue una de las razones de su existencia. "Al nacer, la Revolución rusa aglutinó a su alrededor un mundo de admiradores y de fieles", señalaba François Furet, pretendiendo

\footnotetext{
${ }^{1}$ Hobsbawm, Eric; Historia del siglo XX, 1914-1991; Crítica; Barcelona; 1995; p. 63.

${ }^{2}$ Nolte, Ernst; Después del comunismo; Ariel; Barcelona; 199; p. 41.
}

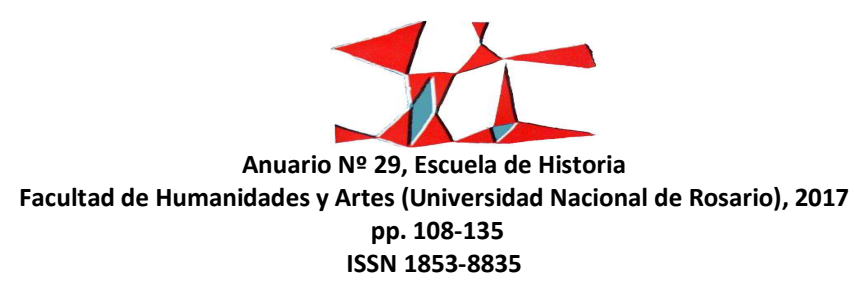




\section{Buenos Aires-Moscú. El partido comunista argentino y la Revolución Rusa hasta los años treinta}

explicar, desde la hostilidad a su objeto de estudio, lo que denominaba el "embrujo universal de octubre". Puede decirse que el Partido Comunista (PC) de la Argentina (o PCA) fue capturado completamente por él.

En efecto, la Revolución rusa de 1917 incidió decisivamente en la historia del PC durante sus primeras tres décadas. Si bien el impacto del proceso ruso se extendió a muchos otros ámbitos, fue a través de esta fuerza como el fenómeno soviético y la Internacional Comunista (IC) o Comintern interactuaron e intervinieron más orgánicamente en el país. Se afirmó: "Cada partido comunista fue el producto del matrimonio de dos consortes de difícil avenencia, una izquierda nacional y la Revolución de Octubre". ${ }^{4}$ No siempre es fácil calibrar cuánto incidieron cada uno de estos factores y cómo se combinaron, a veces, en tensión. EI PCA se constituyó con una militancia que era previa, conformada durante la década de 1910, a partir de un cuestionamiento a los planteos reformistas del socialismo. De esa impugnación, potenciada por una práctica en el medio obrero y juvenil, emergió el Partido Socialista Internacional (1918-1920). Entre las resoluciones primeras de su congreso fundador estuvieron, precisamente, las de expresar apoyo a la Revolución Rusa, así como pronunciarse por el fin de la guerra mundial y abogar por la instauración de repúblicas socialistas en todo el globo. ${ }^{5}$ La figura dirigente inicial del PSI-PC fue José F. Penelón. Sólo después de algunos años se perfilaron los liderazgos de Rodolfo Ghioldi y Victorio Codovilla, precisamente, cuando el PC empalmó plenamente con la dinámica soviética y cominterniana.

De ese modo, el partido fue mutando parcialmente su carácter, adoptando el "modelo ruso" en casi todos los sentidos. Y convirtiéndose en una organización en donde la propaganda y la solidaridad activa con la Revolución constituyeron los elementos esenciales de sus credenciales de identidad. También operó la difusión pública de posiciones y la acción clandestina de la Comintern. EI PSI-PC estuvo entre los primeros partidos comunistas en formarse en América del Sur, circunstancia que le confirió prestigio en la IC. Con la creación, en 1921, del Buró de Propaganda Comunista para Sudamérica, con sede en Buenos Aires, el PC empezó a ser considerada su sección más poderosa, una suerte de representante oficial de la revolución

\footnotetext{
${ }^{3}$ Furet, François; El pasado de una ilusión. Ensayo sobre la idea comunista en el siglo XX; FCE, México; 1995; pp. 76 y 116.

4 Hobsbawm, Eric; "Problemas de la historia comunista"; en E. Hobsbawm, Revolucionarios. Ensayos contemporáneos; Crítica; Barcelona; 2000; p. 13.

5 "Un ardiente e impetuoso soplo revolucionario parece cruzar triunfante por el planeta. Ha comenzado en Rusia y se extiende hacia todos los rincones del mundo. Su móvil: la instauración del socialismo. Con la mirada elevada en tal alto ideal queremos ser en esta sección de América, los agentes eficientes, activos, de esta hondísima transformación revolucionaria", en: Partido Socialista Internacional; Historia del socialismo marxista en la República Argentina. Origen del Partido Socialista Internacional; Buenos Aires; La Internacional; 1919.
}

111

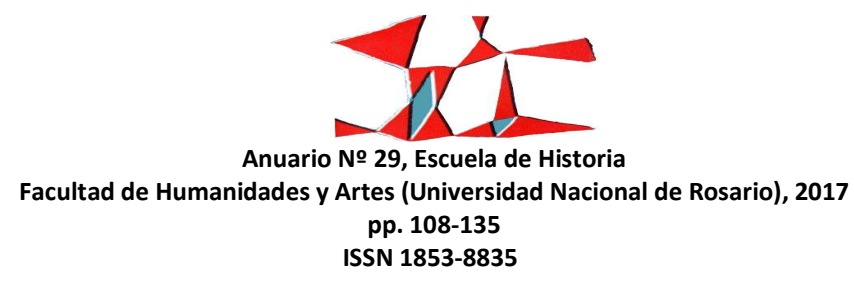


rusa en el subcontinente. Con la bolchevización de 1925 el PCA adoptó el modelo organizacional y todos los elementos de la cultura política comunista de estilo soviético. A partir de 1928-1929 forjó sus caracterizaciones y su programa de revolución por etapas según las directrices de la burocracia soviética y cominterniana, la misma que desde 1935 le impuso la orientación del Frente Popular. ${ }^{6}$

Las desventuras de la Revolución Rusa y la evolución cotidiana de la sociedad, la política, la economía y la cultura soviéticas fueron seguidas paso a paso por el PC. En torno a la URSS giró enteramente el internacionalismo postulado por los comunistas, quienes se presentaban ante la clase obrera con una credencial inequívoca. Ellos eran, sencillamente, los “amigos de Rusia”.

El objetivo de este artículo es aportar algunos análisis acerca de este vínculo entre el PC argentino y la Revolución rusa hasta los años treinta. En un primer punto se explora el papel de los emigrados del régimen zarista, en particular de los judíos arribados a Buenos Aires antes de 1917; entre ellos, se identifica a un grupo específico de militantes, quienes lideraron los procesos de conformación de organizaciones rusas de izquierda y se relacionaron de manera conflictiva con el PC, a pesar de ser una de las referencias más directas de la Revolución en el país. En el segundo apartado se examinan las primeras relaciones entre la Comintern y su sección argentina, a través de la caótica y compleja red de emisarios con la que la Internacional intentó establecer contacto desde su sede en Moscú. Se señala que fue a partir de la preeminencia de Ghioldi y Codovilla en la dirección del PC argentino cuando esa inserción del partido se garantizó plenamente y luego se convirtió en canal para la supeditación a los dictados de la burocracia soviética. La tercera sección de texto está consagrada a la exploración de las múltiples acciones efectivas de solidaridad con la Revolución rusa practicadas por el PC local: actos, manifestaciones y constitución de comités de solidaridad con el pueblo soviético, entre otros. En la parte cuarta se presentan las diversas acciones de propaganda con la URSS desplegadas por el comunismo argentino. $Y$ en el último punto se atiende a la ubicación de dicho partido ante el impacto que la Revolución generó en el mundo intelectual y cultural, en especial, la experiencia de la Asociación Amigos de Rusia.

\footnotetext{
${ }^{6}$ Sobre el PC en esos años en: Camarero, Hernán; A la conquista de la clase obrera. Los comunistas y el mundo del trabajo en la Argentina; 1920-1935; Siglo XXI Editora Iberoamericana; Buenos Aires; 2007. Algunos muy bien fundamentados enfoques globales y parciales sobre el impacto de la revolución rusa en las izquierdas: Doeswijk, Andreas; Los anarco-bolcheviques rioplatenses: 19171930; Cedinci; Buenos Aires; 2013. Pittaluga, Roberto; Soviets en Buenos Aires. La izquierda de la Argentina ante la revolución en Rusia; Prometeo; Buenos Aires; 2015.
}

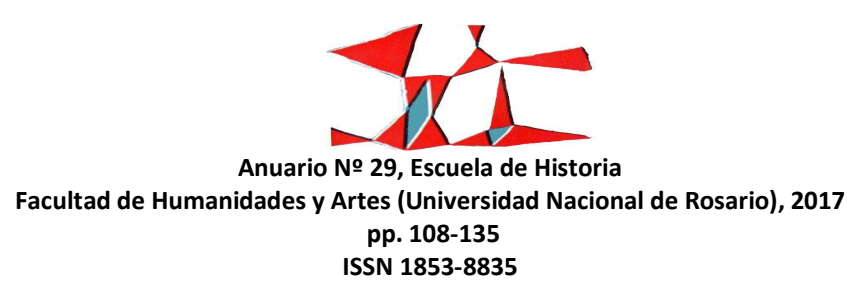


Los vínculos del PC argentino con Rusia se verificaron a un primer nivel básico, a través de la militancia de los emigrados del régimen zarista. Argentina fue el país de América Latina que más inmigrantes recibió del Imperio ruso: unos ciento cincuenta mil entre mediados del siglo XIX y la Revolución. El ingreso más vasto se produjo entre 1901-1910, con un número superior a las ochenta mil personas. Se ubicaron mayoritariamente en Buenos Aires, La Plata y Rosario, y en menor medida en las provincias de Córdoba, Santa Fe, Mendoza y San Luis; un cierto número se situó también en la Patagonia, empleado en las compañías petroleras. Estos inmigrantes presentaron diversidad étnica, confesional y social, sobre todo los del medio rural, que incluían rusos de las estepas del Cáucaso Norte, ucranianos de Jerson, bielorrusos y polacos de la zona de Baranovichi-Brest, judíos de Berdichev y Odessa, a los que se sumaban los "alemanes del Volga". En cantidad de feligreses, la comunidad ortodoxa de Argentina fue una de las más importantes del mundo desde $1890 .{ }^{7}$ Iniciado el siglo XX, una tercera parte de los rusos en el país eran obreros con cierta calificación. Entre ellos, había muchos activistas políticos, escapados de la persecución zarista por su militancia de izquierda.

Ahora bien, un cuarto de los inmigrados desde el imperio zarista a la Argentina, sobre todo en Buenos Aires, era judío; y un gran porcentaje de ellos era proletario, en especial, en las ramas de la confección, el vestido y la industria del mueble. ${ }^{8}$ Ellos incrementaron su número desde comienzos del siglo a partir de la trágica experiencia de los pogroms y, tras la derrota de la Revolución de 1905, con el aumento de la reacción política y la xenofobia antisemita. Poseían un mucho menor nivel de religiosidad que los provenientes de períodos anteriores y de perfil rural, y se hallaban animados por ideas avanzadas y de emancipación social. Los rusos nucleados en torno al uso del ídish constituyeron un mundo propio, con ámbitos bien definidos, animando una red de asociaciones e instituciones que se desplegaba en ciertos circuitos sociales y culturales. Una prolongación natural eran los cafés del barrio del Once, centro de la

\footnotetext{
${ }^{7}$ Nota del Ministro de Negocios Extranjeros de Rusia, 15/04/1890, en el Archivo de Política Exterior de Rusia, citada en Ministerio de Relaciones Exteriores y Culto de la República Argentina y Ministerio de Asuntos Exteriores de la URSS, Argentina-URSS (Rusia). Páginas de historia, 1885-1986. Documentos y materiales. Buenos Aires: EUDEBA; 1990; p. 58.

8 Bilsky; Edgardo J.; "Etnicidad y clase obrera: la presencia judía en el movimiento obrero argentino"; Estudios Migratorios Latinoamericanos; n 11, abril 1989; pp. 27-47. Ver: "Pidiendo el reconocimiento de Rusia"; Revista de Oriente; n²; julio de $1925 ; 28$.
}

113

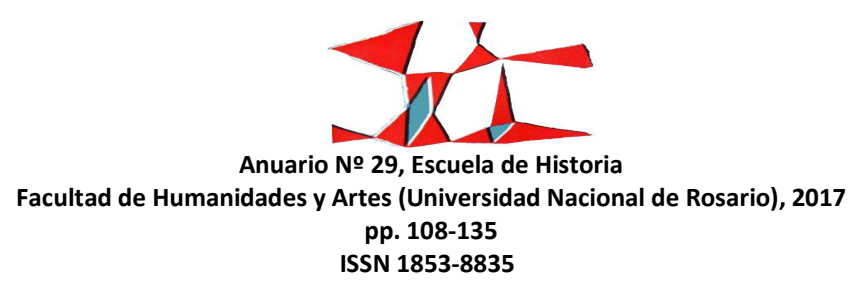


"judería" de la ciudad porteña. Dentro de ese "ghetto abierto", los más frecuentados eran el bar León, ubicado en la esquina de las avenidas Pueyrredón y Corrientes, y el Internacional, fundado por León Paley en 1920, en Corrientes al 2300. Allí, entre los billares, el dominó y el juego de dados, se entretejió un submundo obrero, judío e izquierdista, integrado por quienes habían huido de la represión zarista. César Tiempo (seudónimo del ucraniano Israel Zeitlin) aludía así a uno de esos sitios hacia mediados de la década de 1910: “iBar Internacional / donde la grey semita / inofensivamente se desquita / de las persecuciones de la Rusia Imperial!". ${ }^{9}$ Fue en la Plaza Once donde se realizó el primer gran mitin de las colectividades israelita y rusa para "exteriorizar su júbilo" y "rendirle su homenaje" a la revolución. ${ }^{10}$ Ocurrió el 1 de abril de 1917, cuando 47 agrupaciones judías y rusas realizaron un gran acto púbico en aquella plaza, en donde dirigieron la palabra oradores en castellano, ruso e ídish, para luego marchar hasta la Plaza Lavalle, donde organizaron otro mitin.

La asociación entre ruso y judío, sumada a la presencia que la izquierda tenía en el medio, otorgó a sectores reaccionarios locales y a organismos del propio Estado motivos para reforzar, intercambiar y homologar el antisemitismo y el anticomunismo, bajo el mito del "judeobolchevismo". Esto se había verificado en 1919, cuando, en el contexto de la llamada Semana Trágica, bandas armadas derechistas apoyadas por la policía, que buscaban combatir al "maximalismo", cometieron una suerte de pogrom en algunos barrios porteños: detuvieron, torturaron o asesinaron a casi un centenar de judíos -la mayoría, trabajadores de origen ruso- y devastaron los locales de varias bibliotecas e instituciones obreras de la comunidad. ${ }^{11}$

Ciertamente, el nivel de conciencia política y sindical en la colonia de emigrantes rusos, sobre todo judíos, desde siempre había sido fue muy significativa. A partir de 1905 se fue desplegando un denso entramado asociativo, con varias corrientes recorridas por rupturas y fusiones. Fue muy importante la presencia de los círculos anarquistas, formado por judíos del Imperio zarista o, más en general, de los ashkenazim provenientes de Europa Oriental. Asimismo, estaba el sionismo de izquierda (linkepoalesionismo), con gran influencia entre los judíos rusos. Pero la que más interesa destacar aquí es

\footnotetext{
9 Tiempo, César; Poesías Completas; Stilman Editores; Buenos Aires; 1979.

10 "La revolución rusa. Homenaje de las colectividades israelita y rusa", La Vanguardia, n 3502, 01/04/17.

11 Lewin, Boleslao; Cómo fue la inmigración judía en la Argentina; Plus Ultra; Buenos Aires; 1983; pp 173-206. Lvovich, Daniel; Nacionalismo y antisemitismo en la Argentina; Vergara; Buenos Aires; 2003. Sobre los vínculos del PC en la comunidad judía local: Kersffeld, Daniel; Rusos y Rojos: judíos comunistas en los tiempos de la Comintern; Capital Intelectual; Buenos Aires; 2012.
}

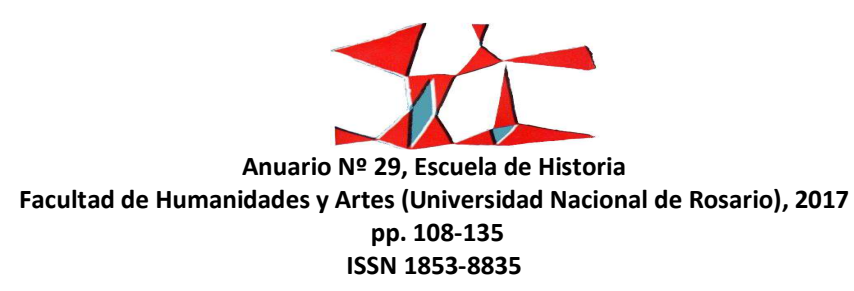




\section{Buenos Aires-Moscú. El partido comunista argentino y la Revolución Rusa hasta los años treinta}

otra tendencia, la que en 1907 creó la Organización Socialdemócrata Obrera Judía Avangard, que editó el periódico en ídish Der Avangard. Los grandes debates internacionales conmovieron a la agrupación, que al poco tiempo se dividió. Por un lado, quedaron los bundistas, defensores del uso exclusivo del ídish y de una organización socialista judía autónoma, entre los que se destacaba Pinie Wald. Por el otro lado, se conformaron los iskrovzes o iskristas, favorables a integrarse al PS y sostener su política dentro de la colectividad. Con el tiempo, estos últimos adoptaron las posiciones asimilacionistas propugnadas por Lenin desde el periódico ruso Iskra. Hacia marzo de 1908 los iskristas constituyeron el Circulo Ruso, al cual el PS por el momento admitió como agrupación idiomática, bajo la denominación de Centro Avangard. Desde esa entidad se publicó un periódico en ídish, llamado Di Shtime fun Avangard (La Voz de la Vanguardia). ${ }^{12}$ Un organismo importante de la colonia durante ese período fue la Biblioteca Rusa, fundada en 1906 por militantes mayoritariamente judíos, que organizaba actividades artísticas, conferencias y debates, y cuya dirección era disputada entre bundistas e iskristas. ${ }^{13}$ Durante las acciones represivas previas al Centenario de 1910, la sede, en donde se albergaba una de las mayores colecciones de libros y revistas en ídish y ruso, fue asaltada; y ello volvió a ocurrir durante la Semana Trágica.

El Centro Avangard no continuó, pues el PS, en función de su política de disolución de todas las secciones idiomáticas, ordenó desactivarlo en 1914. Los sectores iskristas, sin embargo, siguieron como núcleo, editando la revista Golos Avangarda, al tiempo que colaboraban con el grupo de Paris de ayuda a la fracción bolchevique. Al poco tiempo, se sucedió una cadena de emprendimientos asociativos, ya muy relacionados con los eventos que conmovían al país de origen de los emigrados. Hacia 1916 se formó un Comité de Ayuda a los Desterrados y Trabajadores Forzados de la Rusia Zarista. Estallada la revolución de febrero de 1917, este organismo tomó el nombre de Comité de Ayuda a los Diputados Obreros, Soldados y Campesinos. Sobre la base de este último se constituyó luego la Unión Obrera Socialista Rusa. Y fue ella la que, por último, hacia comienzos de 1921 se convirtió en el Grupo Comunista Ruso (GCR), al ingresar al recién constituido PC, junto a la Agrupación Comunista Israelita Avangard. El GCR se mantuvo activo durante buena parte de la década de los veinte. En paralelo a ello, entre fines de 1917 y comienzos de 1918 se creó la Federación de Organizaciones Obreras Rusas de Sudamérica (FORSA), con importante actividad en los años siguientes. Declaró poseer una adhesión de casi 15.000 trabajadores, lo cual seguramente es una

\footnotetext{
12 Laubstein, Israel; Bund. Historia del movimiento obrero judío; Acervo Cultural; Buenos Aires; 1997.

${ }^{13}$ Katz, Pinie; Páginas selectas; ICUF; Buenos Aires; 1980.
}

115

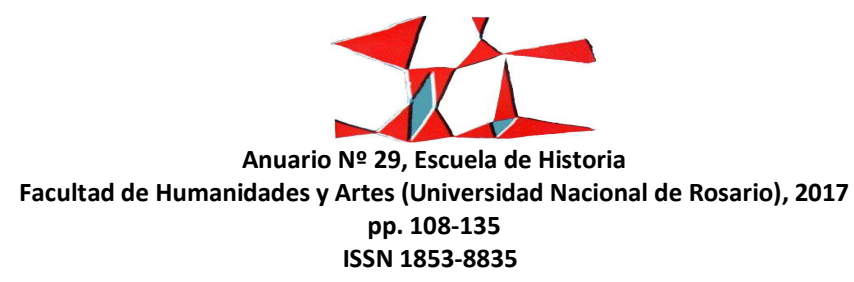


exageración, aunque es cierto que contó con presencia no sólo en el país, sino también en Brasil, Uruguay y Paraguay. Durante varios años la FORSA editó el periódico Golos Truda (La Voz del Trabajo).

Entre los militantes a destacar, por supuesto, emerge, por su espectacularidad, el caso de Simón Radowitzky, asociado durante esos años en la Argentina a la figura del ruso subversivo y revolucionario vindicador. Sin embargo, sus trazos en el país habían sido muy tenues. Apenas un año y medio después de arribar, cometió el atentado e inició su largo encarcelamiento de más de dos décadas. ${ }^{14}$ Pero nos interesa destacar otros hombres y mujeres, menos conocidos, pero que tuvieron su importancia: Mayor Semionovich Mashevich, Ida Isakovna Bondareff, Mijail Alexeevich Komin-Alexandrovsky y Mijail Efimovich Yaroschevsky. ${ }^{15}$ Sus vidas estuvieron signadas por elementos comunes: una edad relativamente similar, su condición judía, la temprana adhesión a la militancia revolucionaria en Rusia, los pesares de la represión y el exilio obligado, el arribo a un país lejano como Argentina hacia la misma época, su inserción en el movimiento obrero y socialista, sus difíciles vínculos con el PCA y, durante los años veinte, su regreso definitivo a la URSS, tras haber permanecido en la Argentina poco más o poco menos de una década y media.

El que más tempranamente arribó a la Argentina y primero retornó a su país de origen, fue Mashevich. Había nacido en marzo de 1884 en Ucrania, en la región de Kajovka. Se desempeñó como trabajador textil, heredando el origen obrero de su familia judía. Durante su precoz militancia en el movimiento obrero local sufrió los efectos de la represión, y hacia comienzos de siglo emigró a Buenos Aires. Fue uno de los miembros principales de la Organización Socialdemócrata Obrera Judía Avangard y de la corriente iskrista, y de los que más sufrió la represión del Centenario. Tras el asalto a la Biblioteca Rusa, a Mashevich y a otro militante, L. Jazanovich, se los colocó bajo las normas de la Ley de Defensa Social y, por ello, fueron deportados del país. Mashevich debió permanecer exiliado un breve tiempo en los países vecinos. Luego de su retorno, se convirtió en uno de los principales referentes de la Unión Obrera Socialista Rusa y del posterior GCR.

\footnotetext{
${ }^{14}$ Bayer, Osvaldo; Los anarquistas expropiadores, Simón Radowitzky y otros ensayos; Galerna; Buenos Aires; 1975.

15 Entre otros, ver: Lazar S. Jeifets y Víctor L. Jeifets; América Latina en la Internacional Comunista, 1919-1943. Diccionario Biográfico; Ariadna Ediciones; Santiago de Chile; 2015.
}

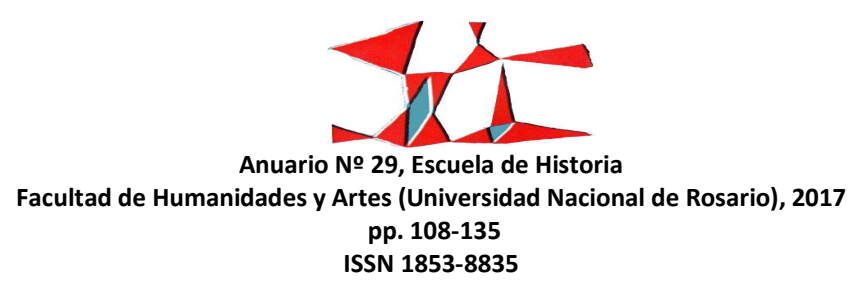




\section{Buenos Aires-Moscú. El partido comunista argentino y la Revolución Rusa hasta los años treinta}

Bondareff había nacido en 1887 en la ciudad ucrania de Yuzovka (actual Donetsk). En 1903 se incorporó al POSDR y al año siguiente fue detenida junto a varios otros militantes de su ciudad natal y enviada a la cárcel de Lugansk, en la que permaneció durante seis meses. Amnistiada luego del Manifiesto de Octubre de 1905, volvió a la lucha. Condujo a la manifestación a los soldados de la guarnición de Kiev. Pero pronto debió emprender el exilio. En 1906 se trasladó a Suiza, formando parte del grupo de apoyo al POSDR en la ciudad de Lausana. Tras nacer en Viena su hija, en 1908 los acabaron instalados en la Argentina. Aquí, ingresó a estudiar Biología en la Facultad de Ciencias Exactas de la Universidad de Buenos Aires y reinició su militancia. Formó parte de la mencionada organización Avangard y devino luego en otro de los referentes claves de la tendencia iskrista. Actuaba como corresponsal local del periódico de los bolcheviques en el exilio, Proletarii. Hacia 1914 la encontramos organizando cursos de economía marxista y sosteniendo posiciones leninistas frente a anarquistas y bundistas, al tiempo que editaba la revista Golos Avangarda. Su vida personal y profesional experimentó cambios: se separó de su marido (quien retornó a Rusia), y constituyó una nueva pareja con otro cuadro comunista, Moisés Kantor. Si bien se graduó como bióloga, acabó trabajando como odontóloga, en un consultorio que derivó en lugar de reuniones clandestinas. Tras la revolución de 1917 encontramos a Bondareff como vocal del Comité pro Rusia Libre, constituido a mediados de abril de ese año, con el fin de recaudar fondos para enviar al nuevo régimen, sobre la base de que "es indispensable la ayuda de todos los simpatizantes con la gran obra de la regeneración política y social de Rusia, de todos aquellos para quienes son caros los ideales de la libertad y del derecho, trazados en la bandera roja de la revolución rusa" ${ }^{16}$ Ella fue una de las animadoras de la fracción bolchevique en el país, convirtiéndose en figura del GCR. Se destacó como organizadora y oradora de la manifestación de solidaridad con la Revolución Rusa y de júbilo por el fin de la guerra del $1^{\circ}$ de diciembre de 1918, la cual fue apoyada por el PSI, agrupaciones socialistas eslavas y del PS, y algunos sindicatos. Cuando el PCA se fundó y aceptó las 21 condiciones de la Comintern, ingresó a sus filas y se hizo miembro de la redacción del periódico Proletarskoye slovo (luego, Kommunisticheskoye slovo). En las filas del partido local, Bondareva fue una de las principales impulsoras de la Comisión Central Femenina (en diciembre de 1922), que editó el periódico Compañera. Sin embargo, luego su militancia en la organización local estuvo cruzada por los conflictos internos, pues debido a su posición frente a la ruptura del grupo

\footnotetext{
16 “La revolución rusa”, La Vanguardia, n 3522, 21/04/17.
}

117

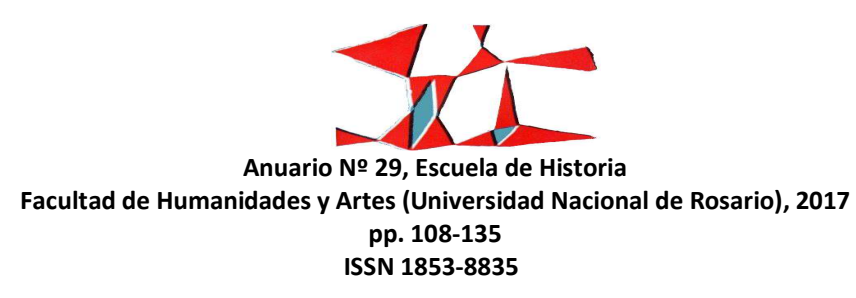


"chispista", fue expulsada del partido hacia 1925-1926, y posteriormente acabó retornando a la URSS definitivamente.

Alexandrovsky había nacido en noviembre de 1884 en la ciudad rusa de Nizhny Nóvgorod. Siendo un muy joven trabajador mecánico se acercó al Circulo Obrero Marxista y al POSDR. Desde esa temprana militancia se sumó a la Revolución de 1905, con una participación en la insurrección armada en el distrito industrial de Sórmovo, a orillas del río Volga. Tras ello, intervino en el movimiento huelguístico en la cuenca ucraniana del Donbass (Donets); en esa zona hacia 1907 integró el Comité del POSDR en Yuzovo-Petrovsk, donde resultó detenido, aunque luego liberado bajo fianza. Tras seguir militando en la clandestinidad, en noviembre de 1908 fue procesado en contumacia (negándose a comparecer en juicio) y condenado al destierro perpetuo en Siberia. Finalmente, logró salir de manera ilegal hacia Alemania y desde allí, emprendió el exilio en Argentina, a la que arriba en 1909. En Buenos Aires volvió a trabajar como mecánico y recomenzó su militancia política y sindical, siguiendo el mismo camino de los otros, en la organización Avangard y el iskrismo. Pero donde Alexandrovsky jugó un papel clave fue en la creación de la FORSA, de la cual fue uno de sus líderes y el director de su periódico.

El último en ingresar y el que menos permaneció aquí fue Yaroschevsky, nacido en enero de 1880 en el seno de una familia judía de clase media asalariada de Besarabia. Tras realizar estudios en Lituania y Petrogrado, y servir como soldado en el ejército del zar, se hizo miembro del Bund y fue detenido en Rusia en 1914. Pero casi inmediatamente logró escapar a la Argentina. Aquí se vinculó a la corriente que conformó en 1918 el PSI. Durante los dos años siguientes, Yaroschevsky se destacó como el traductor de textos marxistas del ruso al castellano, en especial, las obras de V. I. Lenin, tales como Lecciones de la Comuna, El Estado y la Revolución y El Socialismo y la Guerra.

Estos cuatro militantes, y otros como ellos, fueron una de las personificaciones de la revolución rusa en la Argentina. En buena medida congregaron todo lo odiado por el nacionalismo antiobrero, anticomunista y antisemita de ese período: eran rusos, judíos, maximalistas y trabajadores (el orden de variables "desagradables" para la reacción podía variar). A su vez, las relaciones del PSI con estos militantes rusos estuvieron signadas por la desconfianza. Ellos ingresaron al partido tardíamente, al convertirse éste en PC, pero lo hicieron en conflicto; y esa incorporación fue fugaz, antes del regreso definitivo a su país de origen. Los lazos entre los propios emigrados no fueron los mejores. Se produjeron disputas entre ellos

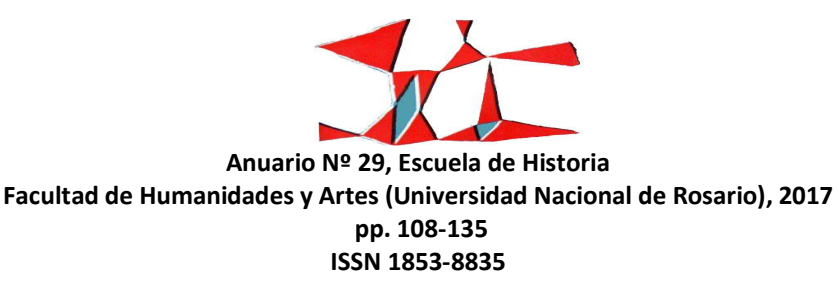




\section{Buenos Aires-Moscú. El partido comunista argentino y la Revolución Rusa hasta los años treinta}

cuando llegó la hora de pautar formas de representación e ingreso de Argentina en la Comintern, y a su vez, colisionaron con los dirigentes del partido local.

El PC argentino había definido de un modo temprano su adhesión a la Internacional Comunista. Sin embargo, estas relaciones con la Comintern no fueron fáciles de garantizar en los primeros tiempos. Por supuesto, influyeron la lejanía, las imposibilidades legales, las dificultades de transporte y la carencia de fondos partidarios para establecer los nexos con Moscú. De hecho, los lazos del PCA con la IC se fueron estableciendo de a poco y en varios pasos, de manera caótica y asistemática. Los primeros vínculos, precisamente, se anudaron a través de Mashevich y Alexandrovsky, en rivalidad. ${ }^{17}$ Como vimos, la trayectoria de Mashevich se entroncaba con la Unión Obrera Socialista Rusa y su heredero, el Grupo Comunista Ruso. Además, sus vínculos eran con la FORA IX ${ }^{\circ}$ Congreso y, en cierta medida, con la corriente de izquierda socialista fundadora del PSI. Alexandrovsky, en cambio, era de la FORSA y con caracterizaciones y estrategias que diferían de las del partido de Penelón, Codovilla y Ghioldi. Encontraba potencialidad revolucionaria en la FORA $V^{\circ}$ Congreso y en los grupos anarcosindicalistas y anarcobolcheviques, algo en lo que el PSI-PCA no depositaba expectativa. La FORSA acusaba a la Unión de tener tendencia "menchevique" mientras que esta última reputaba a la primera como "anarquista". En cualquier caso, para la IC, ellos contaban con el favor del manejo del idioma, de su nacionalidad de origen y de poseer una trayectoria de militancia revolucionaria posible de ser conocida y valorada en las estructuras bolcheviques.

Pero ocurría que las atribuciones de este tipo de delegados no estuvieron claramente definidas por la IC en sus comienzos, por lo menos hasta 1922. Si bien todo era expresión de una forma de control de la Internacional sobre las secciones nacionales, las labores de estos cuadros debían desplegarse en estrecho contacto con el Comité Central de cada partido. En cualquier caso, de hecho, Mashevich y Alexandrovsky (en algún sentido, también Yaroschevsky) reportaron, o al menos ellos quisieron asumir ese papel, como

\footnotetext{
17 Jeifets, Víctor L. y Jeifets, Lazar S.; "La Internacional Comunista y la izquierda argentina primeros encuentros y desencuentros"; en Archivos de historia del movimiento obrero y la izquierda; año III, n 5, septiembre; Buenos Aires; 2014; pp. 71-92. Campione Daniel, López Cantera, Mercedes F. y Maier, Bárbara (comps.); Buenos Aires-Moscú-Buenos Aires: los comunistas argentinos y la Tercera Internacional. Primera parte (1921-1924); Ediciones del CCC Floreal Gorini; Buenos Aires; 2007.
}

119

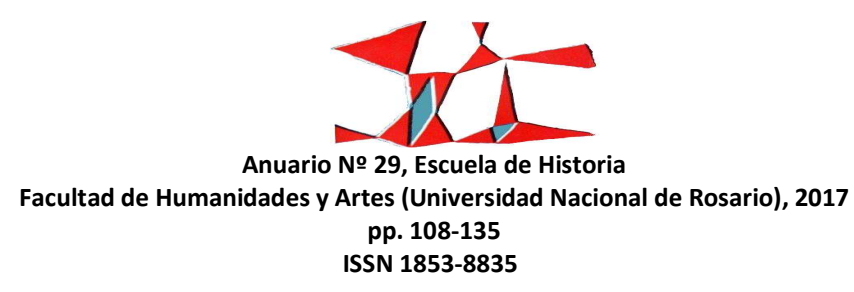


una suerte de ojos y oídos de Moscú en el comunismo argentino, al menos hasta 1921-1922, sacando provecho de sus viajes entre Moscú y Buenos Aires. Sólo que lo hicieron de manera descoordinada, dadas las diferencias que los separaban y los mandatos cruzados. A ello se sumaba la desconfianza del partido argentino hacia esos militantes rusos, carentes de legitimidad dentro de la organización. También estuvo la presencia de otro enviado bajo confianza de Zinoviév, el argentino-alemán Félix Weil. ${ }^{18}$

Hubo aquí un rompecabezas de travesías entre Moscú y Buenos Aires (con interferencias de México), intercambio de informes, documentos y aporte económico, rivalidades apenas encubiertas e intervención de los dirigentes argentinos. En definitiva, hubo una disputa concreta por quien expresaba las credenciales simbólicas y materiales de la Revolución Rusa, la Internacional y las banderas del comunismo en la Argentina y la región. Tras años de enfrentamiento, todo acabó con una victoria de la dirección del PCA y una derrota de estos primeros emisarios rusos cominternianos. Ello encierra la paradoja de que el PCA encaró la "rusificación" de su organización y su plena inserción en las estructuras de la IC, colisionando con los emigrados y emisarios rusos que recalaron en su territorio. Significó un primer triunfo de la dirección local (representada por Penelón, Ghioldi, Codovilla y Pedro Romo, entre otros). Fue una lucha por la autonomía y por mantener márgenes de poder para diseñar su política y su dirección, e incluso, su preponderancia en el mundo comunista del Cono Sur latinoamericano.

Los enviados rusos mandados por el Comité Ejecutivo de la IC (CEIC) siguieron. En el ciclo 1926-1927 fue el turno de Boris Mijailov ("Williams”), quien rápidamente hizo juicios críticos sobre el funcionamiento del PC argentino y se enfrentó a Penelón, lo que derivó en la ruptura de éste y su grupo, con lo cual el partido quedó definitivamente bajo la dirección de Codovilla y Ghioldi. ${ }^{19}$ Si la presencia de estos enviados evidencian los altos niveles de dependencia que las secciones nacionales poseían con la IC, al mismo tiempo, muestran cómo no existía un sistema único de enlaces organizacionales entre el cuartel general de Moscú y los partidos locales, sobre todo de América latina, sino distintos modelos de interacción, que cambiaban sobre la marcha.

\footnotetext{
${ }^{18}$ Camarero, Hernán; "Félix Weil y un libro pionero sobre la historia del movimiento obrero y las izquierdas en la Argentina"; The Internacional Newsletter of Communist Studies Online; n²3; año XVl; Köln; 2010; pp. 60-68.

19 Jeifets, Víctor L. y Jeifets, Lazar S; El Partido Comunista de Argentina y la III Internacional. La misión de Williams y los orígenes del penelonismo; Nostromo Ediciones; México; 2013.
}

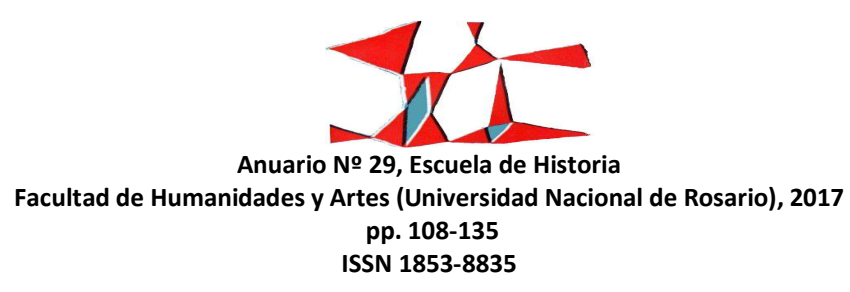




\section{Buenos Aires-Moscú. El partido comunista argentino y la Revolución Rusa hasta los años treinta}

Si bien inicialmente, el PC argentino no había gozado de la plena confianza de la IC en la región, por lo cual el centro de gravedad de la misma quedó por un tiempo depositada en el partido mexicano, las cosas luego cambiaron. Ello puede advertirse al seguir las formas de organización cominterniana en el continente: inicialmente con el Buró Latinoamericano, luego con el Buró de la Propaganda Comunista para América del Sur y, a partir de 1925 y ya bajo el sostén principal del PC argentino, con el Secretariado Sudamericano (SSA), el órgano regional de la IC que más tiempo funcionó en el hemisferio occidental. Eso habría sido el resultado de una suerte de nuevo "modelo argentino-céntrico del trabajo de la Comintern en América del Sur", que comenzó cuando en 1921 el PC argentino fue plenamente reconocido como sección y más claramente desde 1922 cuando el mismo fue considerado base de la expansión comunista en Sudamérica (y el SSA fue concebido casi como la "Internacional de Buenos Aires").

Se ha sostenido que el PC argentino, sobre todo, desde la mitad de la década del veinte, era el más confiable y con vocación de liderazgo en Latinoamérica, además de estar inserto en un país al que la IC podía entender mejor (la lucha de clases adoptaba formas cercanas a las del Viejo Continente) y en el que la comunicación con la organización mundial estaba facilitada por la gran cantidad de inmigrantes europeos. ${ }^{20}$ Quizás eso explique por qué son tantos los cuadros del partido argentino que, en los años siguientes, visitaron distintas secciones latinoamericanas $y$, actuando como virtuales interventores, desplazaron a las direcciones vigentes o alteraron sus líneas políticas. Asimismo, fue importante el envío de militantes argentinos a las escuelas de formación política en la URSS. ${ }^{21}$ Esta estrecha relación del PC argentino con la IC y la URSS no implicó, necesariamente, que recibiera un fuerte sostén financiero. Contra las usuales visiones conspirativas que hablaban del "oro de Moscú", es decir, de un partido al que se le insuflaba vida sólo a partir del apoyo económico soviético o cominternista, la realidad es que, durante los años veinte y los treinta, los fondos recibidos del exterior parecen haber sido limitados o restringidos a fines específicos.

${ }^{20}$ Caballero, Manuel; La Internacional Comunista y la revolución latinoamericana, 1919-1943; Nueva Sociedad; Caracas; 1987, pp. 77-78.

${ }^{21}$ En 1926 fue creada en Moscú la Escuela Leninista Internacional, que ofrecía cursos con una duración mínima de 9 meses. Entre 1926 y 1936, los partidos comunistas latinoamericanos enviaron allí a 120 de sus cuadros, de los cuales una veintena provinieron de Argentina. Los dos primeros fueron Antonio Cantor (1926-1928) y Salomón Elguer (1927-1930). La mayoría llegó luego de 1931. Al retornar a sus países, muchos de esos cursantes se convirtieron en dirigentes de sus respectivos partidos.

121

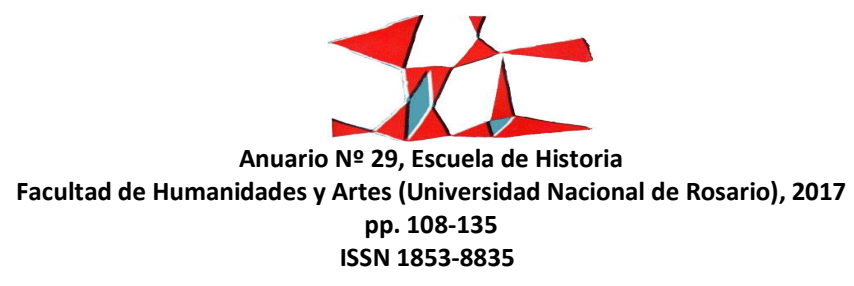


Más allá de los vínculos directos con el estado soviético, la Comintern y los militantes y emigrados de origen ruso, estaba el apoyo activo y el reconocimiento que el PC argentino hacía a la Revolución de Octubre y al régimen que la heredó. Las formas en que se manifestó esa adhesión fueron múltiples.

La solidaridad con la Revolución Rusa se expresaba, ante todo, en la arena pública. A partir de 1918, todos los 7 de noviembre, aniversario de la toma del Palacio de Invierno, el partido realizaba grandes concentraciones en la ciudad de Buenos Aires (que a veces también se replicaban en otros centros urbanos del país, como Rosario y Córdoba). Era el principal evento organizado por el PC, junto a los actos con motivo de la conmemoración del día internacional de los trabajadores, el $1^{\circ}$ de mayo. Durante la década de 1920, especialmente en la segunda mitad, cuando el partido gozó de márgenes de legalidad, los comunistas se jactaban de reunir regularmente entre 10.000 y 15.000 simpatizantes en sus manifestaciones de conmemoración de dicha revolución. Esas actividades tenían un periplo recurrente, en el que se combinaban actos con múltiples tribunos y desfiles entre la Plaza Once, la Plaza de los dos Congresos y los bordes de la Plaza de Mayo (la Diagonal Sur), acompañados por cánticos, bandas musicales y carteles que identificaban cada una de las columnas. ${ }^{22}$ Junto a las marchas y desfiles, estaban los actos en sitios cerrados. Por caso, en noviembre de 1929, el PC festejó el duodécimo aniversario de la Revolución Rusa en un teatro porteño, con un festival en el que se sucedieron cantos, declamaciones y representaciones artísticas de las agrupaciones lituana, húngara, ucraniana, yugoslava, búlgara, italiana y judía, cada una. ${ }^{23}$ En el festival, cada agrupación se expresó en su propio idioma. Existen muchos otros ejemplos que reafirman el carácter plurilingüe adoptado por la propaganda comunista y el modo en que ésta siguió girando en torno a la identificación con la gesta bolchevique.

Durante la década de 1920, la existencia de organismos específicos del PC argentino en apoyo a la clase obrera y el pueblo de Rusia se extendió a todos los planos. Entre 1921-1922 la Rusia soviética afrontó una grave hambruna en varias zonas, pero con especial intensidad en la región del Volga, en la que murió cerca de un millón de personas. Ello fue producto de múltiples causas: la interrupción de la producción

\footnotetext{
22 "Más de 10.000 trabajadores testimoniaron el 7 de noviembre su adhesión incondicional a la revolución rusa", La Internacional, $\mathrm{n}^{\circ} 3161,13 / 11 / 26$. "Fue grandiosa la manifestación conmemorativa del $\mathrm{X}$ aniversario de la Revolución Rusa", La Internacional, $\mathrm{n}^{\circ}$ $3213,12 / 11 / 27$. "Diez mil personas desfilaron en la manifestación con que el Partido Comunista conmemoró la Revolución Rusa", La Internacional, $\mathrm{n}^{\circ}$ 3266, 17/11/28. “La gran demostración comunista del 7 de noviembre”, La Internacional, $\mathrm{n}^{\circ}$ 3319, 16/11/29.

23 "Grandioso festival conmemorando el XII aniversario de la Revolución Rusa", La Internacional, n³317, 2/11/29.
}

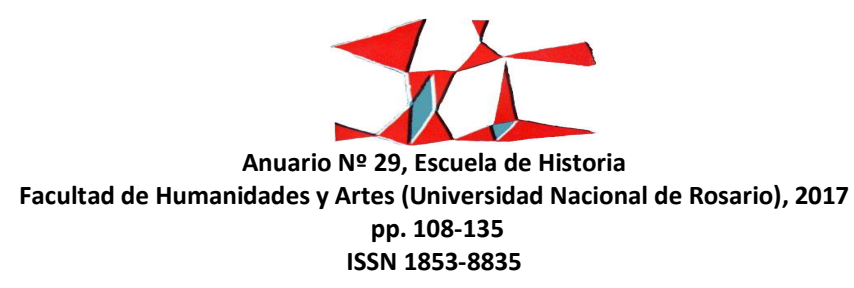




\section{Buenos Aires-Moscú. El partido comunista argentino y la Revolución Rusa hasta los años treinta}

agrícola tras casi siete años de guerra, la constante prioridad en el envío de alimentos para los frentes de batalla, la retención de grano por kuláks y sacerdotes, las medidas de requisas, que se le sumó al fortuito hecho de ocurrir una de las más fuertes sequías de la historia, que arruinó cerca de un cuarto de lo sembrado. Ante esta situación se fueron conformando diversos comités de solidaridad. En 1921 los comunistas constituyeron un Comité de Ayuda al Pueblo Soviético (luego denominado Comité de Ayuda al Proletariado Ruso), que se encargaba de reunir comestibles, ropa y dinero para enviarlos al régimen de Moscú. ${ }^{24}$ La sede de la institución se hallaba en Sarmiento 2616, en el barrio porteño de Balvanera. Como colateral de la misma, en 1923 también se conformó el Comité Infantil de Amistad con los Niños Rusos, lo cual también era una política impulsada por la IC en todo el mundo. El personaje de Tita, la sufriente y abnegada niña lustrabotas de un cuento que Elías Castelnuovo escribió en 1924, aparece integrando este Comité. ${ }^{25}$ Una fotografía de aquel año exhibía en Compañerito, la revista para niños del PC, a un centenar de chicos que formaban parte de ese organismo, sentados, con banderas rojas que cruzan sus pechos y con alcancías en las manos, listos para recaudar dinero, frente al local del Comité de Ayuda al Proletariado Ruso. ${ }^{26}$ Todavía algunos años después, en mayo de 1927, aparecía un balance de su labor en el diario La Nación, en el que se sostenía que esta última institución “... ha venido realizando una labor de socorro a los trabajadores rusos, por medio de colectas, venta de juguetes rusos en la Argentina, venta de colecciones de sellos postales, de fotografías, exhibición y venta de películas rusas, todo ello para allegar recursos a los obreros rusos que lo necesitaren". ${ }^{27}$ El Comité de Ayuda existió hasta finales de los años veinte, cuando se transformó en otra entidad de solidaridad, llamada Socorro Obrero, que se comportaba como sección argentina de Socorro Obrero Internacional (otra organización creada por la Comintern).

La voluntad comunista por expresar esta solidaridad y homenaje a través de comités y organismos se mostraba con el despliegue de prácticas rituales, a veces, desproporcionadas. Eso pudo advertirse, por ejemplo, en los esfuerzos del PC por formar comités de recepción a los "marinos rojos" que llegaron al Río de la Plata: tal el caso del que se formó, en junio de 1925, para recibir al vapor Vaslav Vorovsky, el primer buque desde la Revolución que iba a flamear la bandera roja del Soviet en el puerto de Buenos Aires

\footnotetext{
${ }^{24}$ En marzo de 1922, el PC informaba que dicho Comité ya había girado a Moscú 2 millones de marcos, reunidos en las colectas: La Internacional, $\mathrm{n}^{\circ} 301,02 / 03 / 22$.

25 "Lázaro"; en AA. VV.; Los escritores de Boedo. Selección; CEAL, Buenos Aires; 1968; pp. 26 y ss.

26 "Por nuestros compañeritos de Rusia", Compañerito [1.a etapa], I, 2, junio de 1923, p. 7.

27 "La policía visitó los domicilios de varios comunistas", La Nación, 28/5/27.
}

123

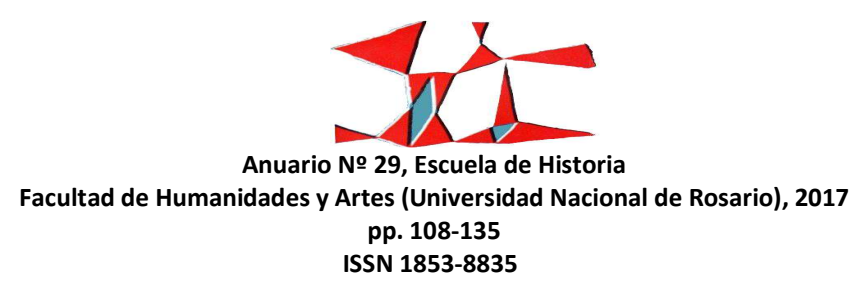


(finalmente sólo alcanzó a arribar al de Montevideo); o el que se constituyó para recibir al Tovarich, el barco escuela ruso que sí pudo llegar a Buenos Aires a comienzos de 1927. En el primer comité de recepción, había una representación de medio centenar de organizaciones obreras; en el segundo, casi setenta y cinco, que incluían sindicatos, bibliotecas y clubes proletarios, y asociaciones de inmigrantes. Cuando llegó el Tovarich, el PC concentró miles de trabajadores en un acto en Plaza Retiro y los condujo hacia el Puerto Nuevo para vitorear a los marinos. ${ }^{28}$

La adhesión a la URSS por parte de los comunistas se expresó también en su lucha contra la guerra, a la que consideraban una amenaza generada por el imperialismo, el fascismo o, en términos más generales, el capitalismo. La guerra que se debía impedir era fundamentalmente contra la Rusia soviética, pero también contra la China revolucionaria, contra los pueblos oprimidos que se oponían a la dominación colonial o la de carácter interimperialista. ${ }^{29}$ El PC llamó a conformar el Comité de Acción contra la Guerra, surgido en junio de 1927, como respuesta a la ruptura de relaciones diplomáticas entre Gran Bretaña y la URSS (producto de los acontecimientos que transcurrían en China), que parecía presagiar el inicio de un conflicto bélico anglo-ruso. Como ocurrió con otras organizaciones de la etapa del frente único, el PC invitó a formar parte de este comité a personalidades independientes o pertenecientes a otras corrientes políticas (como Alfredo Palacios, Honorio Barbieri y Rizzo Baratta), pero, desde el inicio, esa incorporación extracomunista se fue raleando. Este Comité se diluyó, pero la idea volvió a lanzarse en mayo de 1932, cuando se formó el Comité Nacional contra la Guerra Imperialista, con sede en la Liga Antiimperialista. La creación de esta entidad se relacionaba, nuevamente, con una línea impulsada por la IC. Sobre aquella base se formó en agosto de 1932 el Congreso Mundial contra la Guerra Imperialista, surgido en Ámsterdam bajo la dirección de los intelectuales Romaine Rolland y Henri Barbusse. El PC le dio profusa cobertura periodística al Ilamamiento para su realización. El Comité realizó algunos actos públicos, para denunciar una ofensiva bélica sobre la URSS, en función de lo

\footnotetext{
28 "Más de 5.000 personas concurrieron a saludar a los marinos del Tovarich", La Internacional, n 3180, 26/3/27.

29 "Nunca como hoy la guerra imperialista amenaza tanto a la Unión Soviética”, La Internacional, n 3386, 15/2/32.
}

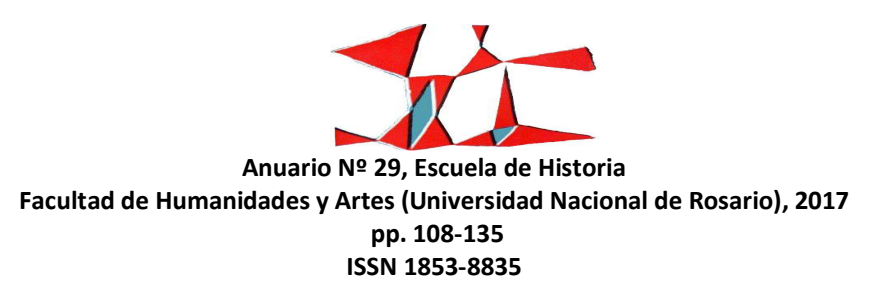




\section{Buenos Aires-Moscú. El partido comunista argentino y la Revolución Rusa hasta los años treinta}

cual se condenaba la ocupación japonesa de Manchuria y las políticas antisoviéticas de Polonia y Francia. ${ }^{30}$

Por otra parte, estuvo la experiencia de la Sociedad de Ayuda a los Colonos Israelitas en la Rusia Soviética (Procor), organización a favor de la colonización judía en la URSS, que en 1928 creyó ver coronados sus objetivos con la finalmente fallida experiencia de la Región Autónoma de Birobidján, en un extremo de Siberia. ${ }^{31}$ El Procor fue constituido en 1924 por delegados de 16 organizaciones obreras, la mayoría comunistas, lo que también se reflejaba en su Comité Ejecutivo. Instaló su sede en Sarmiento 2616 y constituyó subcomités en casi todos los barrios de la Capital, en la mayoría de las provincias del país y hasta en Brasil. En los años siguientes, logró reunir y enviar a Rusia sumas importantes de dinero.

IV

A los vínculos y la solidaridad del PC argentino con la Revolución Rusa y la URSS se le agregaba otra dimensión: la de la propaganda. La presentación idealizada del proceso soviético les servía a los comunistas locales como un elemento vital para la exposición de su proyecto. Se trataba de una de las principales cartas de presentación del partido. Así ocurría cuando sus militantes actuaban en la lucha y organización de la clase obrera. No sólo en los sindicatos y las federaciones gremiales, a los que intentaban insertar en la Internacional Sindical Roja (ISR), con sede en Moscú, sino incluso al nivel más básico, cuando actuaban en las primeras formas de acción en fábricas y talleres. Por ejemplo, en 1934 decía el periódico de la célula juvenil del PC de la Fábrica Argentina de Alpargatas, con el objetivo de contrastar con la difícil situación de los trabajadores de esa empresa textil: "Los jóvenes obreros de la Unión Soviética tienen todo lo necesario para su desarrollo físico, cultural y político. Los jóvenes menores de 18 años trabajan 6 horas diarias y les pagan igual que a los adultos; todos los años les dan de 15 a 30 días de vacaciones con sueldo pago. En las escuelas profesionales o en la fábrica hay bibliotecas, salas de lectura, clubs, cines, etc.", y concluía con el

30 “El mundo se desliza hacia la guerra imperialista mundial”, Mundo Obrero, n 7, 30/08/32.

31 “La solución proletaria de la cuestión nacional y de la colonización judía”, La Internacional, n 3320, 23/11/29.

125

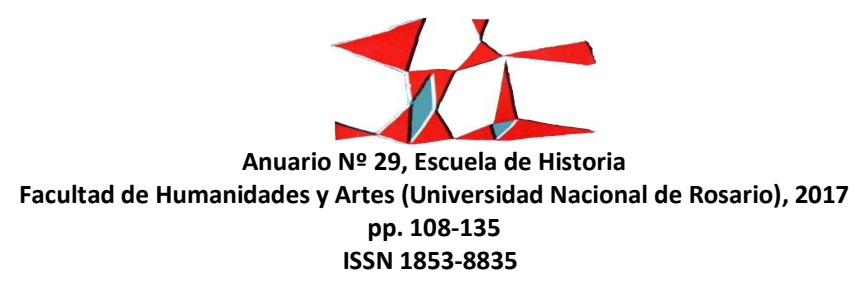


inevitable llamado de marchar "... a la lucha por el poder, para conseguir el bienestar que actualmente tiene únicamente el proletariado de la Unión Soviética". ${ }^{32}$ En otros casos, la lejana gesta bolchevique era evocada como desafío y advertencia a los patrones vernáculos. Por ejemplo, en otra fábrica textil, el periódico comunista respondía a los consejos y retos profesados por el director del establecimiento a los cardadores, por la rotura de una máquina: “iNo amenace, señor director! Mire que la miseria es muy 'mala consejera' y despierta en el que sufre su conciencia de clase, que puede determinar su caída como 'director' y obligarle a vender ciruelas, como ocurrió con muchos peores que Ud. en la Rusia obrera y campesina". ${ }^{33}$

A partir de los años treinta, cuando la desocupación obrera era muy grande en todo el mundo, el PC se encargó de ilustrar una y otra vez cómo en la URSS este problema quedaba definitivamente archivado en el marco de su constante expansión económica. Como informaba el diario impulsado por el PC en 1932, en una de sus tantas notas referidas al tema: "En la Unión Soviética, cada semana se inauguran nuevas fábricas, nuevos altos hornos, nuevos grandes talleres metalúrgicos, etc. En cambio, en los países capitalistas cada día aparece un nuevo Magnitogorsk, al revés...", y lo ejemplificaba con el cierre de un alto horno austríaco de Loeben, que dejaba cientos de obreros desocupados. ${ }^{34} \mathrm{El}$ mensaje era inequívoco: bajo el orden burgués, progresaba la crisis, crecía la miseria y se clausuraban las fuentes de trabajo, pero el Estado proletario demostraba que, en su dominio, lo contrario podía ocurrir.

Y como se trataba de la "sociedad futura", el comunismo hacía campañas prosoviéticas hasta sobre la niñez, apelando a los recursos emocionales y discursivos más básicos. Compañerito, la revista comunista para niños decía acerca de Rusia:

... no existe la odiosa diferencia que existe en otras naciones, la Argentina, por ejemplo, entre niños ricos y niños pobres, entre los niños que poseen todos los juguetes, golosinas, todas las diversiones, y los niños que carecen de todo ello porque sus padres apenas ganan para darles un poco de pan. En Rusia, desde que nacen, los niños son cuidados por el Estado, por las municipalidades, que se encuentran en poder de los obreros y que se llaman Soviets; para ellos existen casas muy grandes,

\footnotetext{
32 "Como viven los jóvenes en la URSS", La Alpargata ("Periódico defensor de los intereses de los jóvenes obreros y obreras de la 'Alpargata Argentina S.A.'”), n 1, julio de 1934.

33 "Consejos patronales", El obrero textil ("Órgano de los obreros y obreras de la fábrica textil Barlaro"), n 5, agosto de 1927.

34 "Magnitogorsk al revés", Bandera Roja, n 42, 13/5/32. Se refería al gran complejo hidroeléctrico e industrial que se inauguró en la URSS como parte del primer plan quinquenal.
}

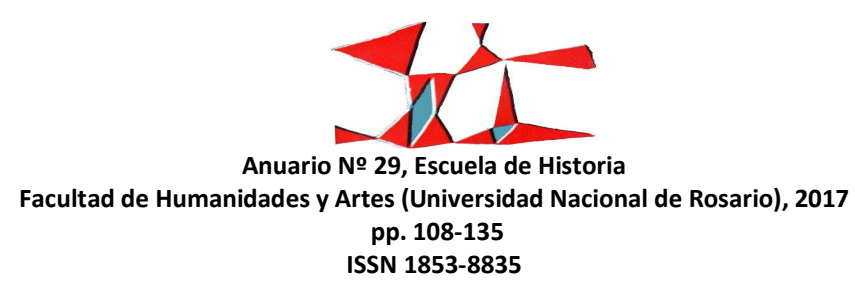




\section{Buenos Aires-Moscú. El partido comunista argentino y la Revolución Rusa hasta los años treinta}

muy limpias, muy blancas, con grandes jardines, con mucha luz. Mujeres bondadosas cuidan de ellos y se preocupan por su salud y por su instrucción. ${ }^{35}$

La reproducción de fotografías de infantes rusos con aspecto de felicidad, desayunando y durmiendo en cómodas instalaciones, pretendían ratificar aquellos argumentos. Asimismo, si el "deporte burgués" era entendido por los comunistas como una práctica corrompida por intereses comerciales, el patrioterismo y el individualismo, el panorama en la URSS siempre era expuesto como la inversión de esta realidad y como el ejemplo vivo que debían emular los clubes obreros y la Federación Deportiva Obrera (FDO) impulsada por el PC, pues aquél era "... el único país donde el deporte no es una farsa ni un privilegio", una suerte de edén para el ejercicio físico, en donde todos lo practicaban, bajo el auspicio del Estado proletario. ${ }^{36}$

Por último, nos interesa explorar cómo el PC se posicionó ante el impacto que la Revolución rusa ejerció en el medio intelectual y cultural argentino, y los modos en los que actuó para construir nuevas instancias de solidaridad con el régimen soviético. Primero es necesario reconocer un fenómeno objetivo: el proceso iniciado en 1917 dibujó una ola de simpatía que fue más allá del espacio del PC y construyó un momento de identidad específico para una camada de hombres y mujeres en el mundo de la cultura. Como se sostuvo: "El encuentro de estos jóvenes intelectuales con la Rusia de los soviets es su punto de diferenciación respecto del resto del campo cultural; el impacto ideológico-político de la revolución se convierte en un leit-motiv de discursos y prácticas artísticas, genera compromisos y articula núcleos intelectuales...". ${ }^{37}$ Más allá de su irradiación general, la cuestión soviética contribuyó inicialmente para acercar a varios intelectuales, escritores y artistas al comunismo. Como había ocurrido en muchos países, en la Argentina, especialmente durante la década de 1920, la revolución se había convertido en un modelo admirable y en una fuente de esperanzas en el ámbito de la cultura, lo que aparece registrado en los discursos y formas estéticas:

\footnotetext{
35 “Los niños en Rusia”, Compañerito, n², junio de 1923.

36 "Nuestro concepto del deporte", Boletín de la Federación Deportiva Obrera, n 1, 24/10/25.

${ }^{37}$ Sarlo, Beatriz; Una modernidad periférica: Buenos Aires 1920 y 1930; Nueva Visión; Buenos Aires; 1988; p. 123.
}

127

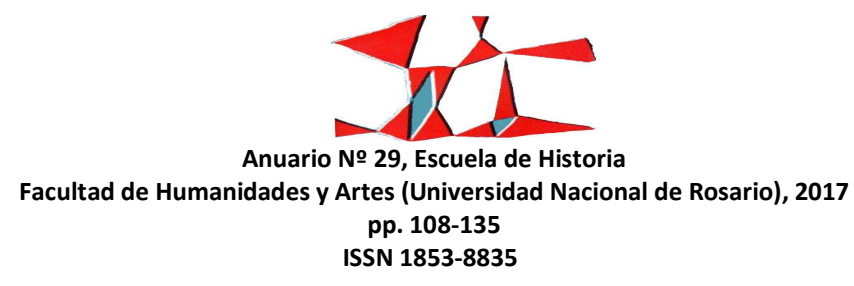


La revolución rusa y los soviets representaban, entonces, un principio de transformación radical, cuyo atractivo residía también en las proporciones épicas de sus actos, en la rapidez con que el cambio pareció realizarse, en la juventud de muchos de sus dirigentes, en el nuevo espíritu que anunciaba al mundo la posibilidad de todas las transformaciones y el trastocamiento de todos los lugares sociales [...] los nuevos intelectuales de izquierda encuentran en la gesta del proletariado ruso un vector que los conduce no al pasado sino al futuro [...]. Más que grandes discusiones, en la primera década de la revolución, Rusia suscita adhesiones y fervor. ${ }^{38}$

En ese medio, aumentó la atracción hacia el PC debido a una serie de factores: la permanencia del ideal del comunismo y de la causa de la Revolución soviética; la creencia en una caída inminente del capitalismo tras la crisis de 1929; la creciente conflictividad social que se vivió a partir de este fenómeno; los vínculos orgánicos con la clase trabajadora que demostraba poseer el partido; el compromiso de lucha que exhibían sus militantes; la búsqueda de una nueva cultura. Incidía la creciente influencia de los comunistas en el movimiento obrero: "Esta mayor inserción debía sin duda resultar atractiva para algunos intelectuales progresistas, máxime cuando esa situación se iluminaba con el contraste entre la crisis capitalista mundial por un lado y lo que se percibía como los éxitos de la construcción del socialismo en la Unión Soviética por el otro". 39

José Ingenieros, en los primeros años veinte, no había sido la única figura intelectual, aunque sí la más importante, en hacer conocer su simpatía y apoyo a la Revolución Rusa: "De ese nuevo espíritu, de esa nueva conciencia social que anima a los hombres jóvenes de todos los países, bien puede ser la revolución rusa un símbolo tan glorioso como hace un siglo lo fuera la Revolución Francesa", escribía Ingenieros en 1924, en su artículo "Glorificación de Lenin". ${ }^{40}$ Incluso, el joven Jorge Luis Borges escribió "Rusia", un poema a favor de la gesta soviética, que se publicó en 1920, en una revista española, que habría sido uno de los que el autor proyectaba editar en un libro llamado Los salmos rojos.

\footnotetext{
${ }^{38}$ Sarlo, Beatriz; Una modernidad periférica: Buenos Aires 1920 y 1930; Nueva Visión; Buenos Aires; 1988; pp. $122-124$.

39 Terán, Oscar; “Aníbal Ponce o el marxismo sin nación”, En busca de la ideología argentina; Catálogos; Buenos Aires; $1986 ;$ p. 159.

${ }^{40}$ Reproducido en Terán, Oscar; José Ingenieros: Antiimperialismo y nación en la Argentina; Siglo XXI, México; 1979. La obra central de Ingenieros referida al tema fue Los tiempos nuevos (1920). Un balance de su posición frente a la Revolución Rusa: Agosti, Héctor P.; José Ingenieros, ciudadano de la juventud; Futuro; Buenos Aires; 1945. Kohan, Néstor; De Ingenieros al Che. Ensayos sobre el marxismo argentino y latinoamericano; Biblos; Buenos Aires; 2000. Acha, Omar; "La revolución rusa de José Ingenieros: elitismo y progresismo"; Herramienta; n² 20, año VII; Buenos Aires; invierno de 2002; pp. 163-182.
}

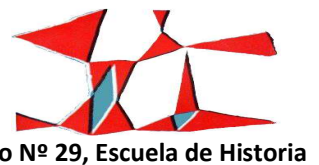




\section{Buenos Aires-Moscú. El partido comunista argentino y la Revolución Rusa hasta los años treinta}

Jorge Luis Borges fue parte de este fenómeno de entusiasmo por las noticias provenientes de Petrogrado y Moscú. El en ese entonces todavía joven escritor argentino, contra lo que él mismo quiso recordar luego, tuvo un período izquierdista, que se había iniciado con fuerza mientras vivió con su familia en Ginebra (Suiza) durante los años de la guerra mundial. En cartas a sus amigos Maurice Abramowicz y Roberto Godel testimonió su admiración con el proceso soviético, el "bolcheviquismo" y la posibilidad que se extendiera a Alemania, escribiendo en diciembre de 1917: "Yo deseo esta revolución con toda mi alma". ${ }^{41}$ Fue la época en la que más se acercó a la idea de la misión del intelectual por la transformación del mundo. Aunque es cierto que apenas dos años después ya manifestó su desazón con el bolchevismo y luego sólo mantuvo durante otros dos o tres años un apoyo general al proceso revolucionario, más allá del régimen gobernante. Trasladado a Palma de Mallorca y Madrid durante algunos meses de 1919 y entre 1920-1921, había concebido un libro, que finalmente decidió descartar. ${ }^{42}$. Se trataba de una veintena de poemas en verso libre, probablemente redactados en sus años suizos, de los cuales al menos tres estaban dedicados a elogiar a la "Revolución rusa, a la hermandad del hombre, al pacifismo", y que iban a aparecer bajo el título de Los salmos rojos o Ritmos rojos. ${ }^{43}$ El poema que más trascendencia tuvo fue "Rusia", al que se sumaron "Gesta maximalista" y "Guardia roja". 44

Posteriormente, mientras surgían nuevas y distintas adhesiones de intelectuales a la revolución bolchevique, se fundó en el país, hacia mediados de 1925, la Asociación Amigos de Rusia. Esta entidad fue promovida por la Comintern hacia esa época en varios países del mundo. Si bien sus labores estaban en consonancia con las políticas y las tareas del comunismo local e internacional, no fue una institución artificialmente sostenida por éste. De hecho, su principal referente fue el Dr. Arturo Orzábal Quintana, un intelectual especializado en política internacional, que siempre manifestó su simpatía por el proceso de edificación de la URSS, aunque nunca perteneció al PC. Se desempeñaba como secretario general de la Unión Latinoamericana/Sección Argentina, la organización fundada por Ingenieros y Ponce, en la que confluían políticos, sindicalistas e intelectuales de distintas procedencias ideológicas, como el ex diputado socialista Alfredo Palacios y el pedagogo Julio R. Barcos, entre otros, y que se expresaba a través del

\footnotetext{
${ }^{41}$ Artundo, Patricia; “Entre 'La aventura y el orden'. Los hermanos Borges y el ultraísmo argentino"; en Cuadernos de Recienvenido, n 10; Universidade de São Paulo; São Paulo; 1999; p. 66.

42 Meneses, Carlos; Borges en Mallorca (1919-1921); Aitana; Alicante; 1996.

${ }^{43}$ Borges, Jorge Luis; Autobiografía; El Ateneo; Buenos Aires; p. 60.

44 "Rusia" luego publicado en Vicente Huidobro, Alberto Hidalgo y Jorge Luis Borges (comps.); Índice de la nueva poesía americana; Sociedad de Publicaciones El Inca; Buenos Aires; 1926.
}

129

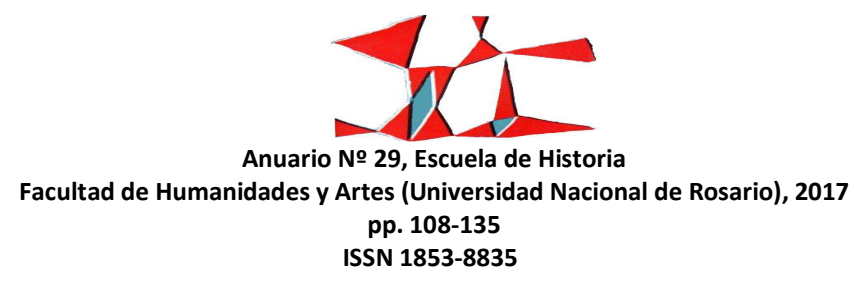


periódico Renovación. Orzábal Quintana no fue el único no comunista de Amigos de Rusia: durante sus primeros meses de existencia, también se incorporaron a esta institución o realizaron actividades con ella figuras como Bartolomé Bosio (uno de los primeros ideólogos e impulsores del sindicalismo en el país) y Carlos Sánchez Viamonte (referente de la Reforma Universitaria de 1918). Los miembros titulares de la institución, elegidos en noviembre de 1925, fueron Orzábal Quintana, Roberto Hinojosa, Honorio Barbieri, Oscar Montenegro Paz, Ramón Rojo y Wenceslao Domínguez, junto a figuras reconocidas del PC como Victorio Codovilla, Manuel Punyet Alberti y Gregorio Gelman (padre del futuro poeta Juan Gelman).$^{45}$ La Asociación entendía que "Rusia encarna hoy el anhelo universal de realizar una humanidad nueva [...], una nueva civilización". Y así presentaba sus objetivos y el tipo de labor que realizaría:

10 Propagar en el ambiente intelectual y obrero del país la obra constructiva que se opera en la Rusia Soviética en el terreno político, económico y cultural. 2으 Luchar por el reconocimiento del gobierno ruso y la iniciación de las relaciones comerciales con Rusia. 3ㅇ Propender a un acercamiento entre círculos obreros e intelectuales del país y los de Rusia [...]. Realizará su acción: a) Mediante la publicación de una revista [...]. b) Mediante conferencias públicas en instituciones culturales y sindicales. c) Creando una Biblioteca con material ruso [...]. d) Realizando reuniones periódicas en las que se leerá, hablará y discutirá sobre asuntos rusos. e) Publicando los folletos u obras de propaganda que se considere necesario. ${ }^{46}$

Amigos de Rusia pareció cumplir estos compromisos. En 1925 y 1926, realizó diversas conferencias públicas, en los salones Unione e Benevolenza y Garibaldi, sobre temas de actualidad, especialmente sobre la evolución de la URSS, que siempre concluían con el pedido de reconocimiento diplomático a ésta por parte de la Argentina. Solía promover, además, a la Sociedad Literaria, Dramática y Musical Rusa, presidida por Marcos Simsilevich y en la que el PC también ejercía influencia. En la Capital, Amigos de Rusia funcionaba, como tantos otros organismos obreros y comunistas, en el barrio de Once, en Sarmiento 2616, sede de distintas instituciones promovidas por el PC, como el mencionado Comité Central de Ayuda al Proletariado Ruso. También tenía filiales en otras ciudades, como Rosario, La Plata y Córdoba.

\footnotetext{
45 “Asociación Amigos de Rusia”, La Internacional, n 1194, 1/12/25.

46 "Propósitos", Revista de Oriente, n 1, junio de 1925.
}

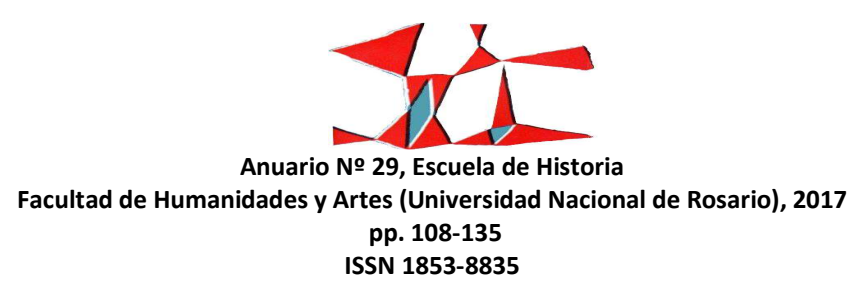




\section{Buenos Aires-Moscú. El partido comunista argentino y la Revolución Rusa hasta los años treinta}

Durante algo más de un año, la asociación aseguró la existencia de la Revista de Oriente, una publicación mensual de excelente calidad gráfica, con una gran tirada y sostenida por una distribución comercial. ${ }^{47}$ Publicaba artículos de cultura, teoría e información general. Entre otros, allí escribieron José Carlos Mariátegui, la poeta chilena Gabriela Mistral, el comisario de Instrucción Pública de la URSS Anatoli Lunacharsky, y los escritores y hombres de la cultura argentinos Julio R. Barcos, Raúl Scalabrini Ortiz, César Tiempo, Álvaro Yunque y Jacobo Fijman. Los intelectuales prestigiados eran los que se acercaban a posiciones favorables a la clase obrera, al antiimperialismo y a la Revolución Rusa: dos de los que más espacio recibieron fueron Barbusse y el fundador del APRA peruano Víctor Raúl Haya de la Torre.

Adoptada la estrategia del tercer período, estas experiencias de relación con otros individuos y sectores de izquierda se hicieron imposibles y fueron concluyendo. Incluso, los propios Orzábal Quintana, Barcos, entre otros, fueron atacados por el PC, calificados como "intelectuales pequeñoburgueses confundidos". Desde entonces y hasta 1935, para ser "amigo de Rusia", hubo que exhibir credenciales más firmes, difíciles de hallar fuera de un radio partidario estrecho. Castelnuovo y Ponce fueron algunos de ellos, quienes realizaron viajes a la URSS y escribieron luego sus pareceres. El primero de ellos, quien venía de participar en periódicos anarquistas y sindicalistas, apenas fue aceptado en esos años desde la óptica comunista: publicó en el diario extensos y elogiosos artículos sobre la URSS a partir de sus experiencias de visitante en 1931, que le sirvieron al autor para editar, en 1933, su libro Yo vi en Rusia. Impresiones de un viaje a través de la tierra de los trabajadores. Pero hasta estos relatos resultaban heterodoxos para el estilo partidario. Ponce, en cambio, fue claramente más aceptado. Tras su regreso de Moscú, en junio de 1935, expresaba:

Rusia es una enorme usina en que todos colaboran porque todos se saben propietarios. Se regocijan o se apenan según que el Plan se realice o se entorpezca [...]. La amenaza guerrera contra la URSS es seria y creciente. Rusia es la primera de las patrias proletarias. De su suerte depende en gran parte el inmediato porvenir del proletariado mundial y de la cultura humana. Para evitar esa catástrofe hay

\footnotetext{
47 Bergel, Martín; “Un caso de orientalismo invertido. La Revista de Oriente (1925-1926) y los modelos de relevo de la civilización occidental”; Prismas. Revista de historia intelectual; n 10; Bernal; 2006; pp. 99-117.
}

131

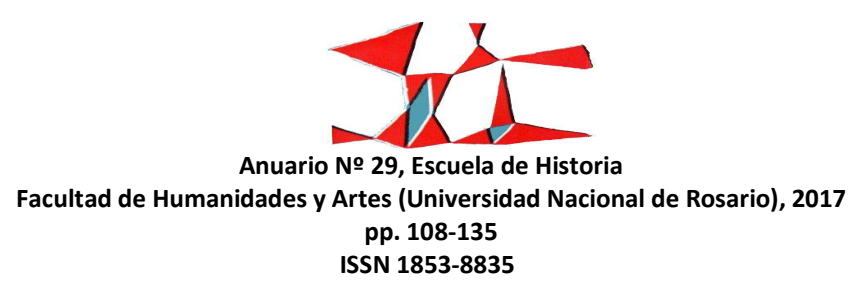


que montar una guardia vigilante alrededor de Rusia. $Y$ esto es obra para obreros y para intelectuales. $^{48}$

La solidaridad y propaganda del PC argentino con respecto a la Revolución Rusa y la causa soviética fue un elemento constitutivo y esencial de la identidad y la cultura política de dicho partido. En el período analizado, sobre todo, 1918-1935, encontramos dos grandes ciclos, con ciertos rasgos característicos. Tras la inicial adhesión al "acontecimiento bolchevique", que tuvo un alcance relativamente ecuménico, pues desbordó ampliamente las filas de la organización y se extendió a diversas capas sociales, políticas e ideológicas que expresaron simpatía con aquél, en los años veinte-treinta, se reconocen dos dinámicas signadas por los avatares de los lineamientos estratégicos del comunismo. Durante la línea del "frente único" (1921-1927), el partido pudo mostrar márgenes de acuerdo con distintos sectores políticos e intelectuales, con el objetivo de promover acciones y organizaciones de solidaridad con la URSS de vastos contornos. Entre otros ejemplos, Amigos de Rusia y varios de los comités señalados, son testimonio de este fenómeno. El advenimiento de la política de "clase contra clase", propia del llamado "tercer período" de la IC (1928-1935), que se orientó sobre concepciones combativas, ultraizquierdistas y sectarias, introdujo el cierre de muchas de las iniciativas de acuerdos más amplios entre el PC y otras expresiones para apoyar a la URSS, campaña que adquirió tonalidades más rígidas, virulentas y exclusivistas.

Durante la primera mitad de la década de 1930, desde la URSS y la Comintern, se emitía un discurso de victoria, que se fue irradiando a todos los partidos comunistas del mundo. Ese espíritu de triunfo de la causa, ese clima de "revolución cumplida", se sostenía en la presunción de que la transformación económica, social y cultural de Rusia finalmente se estaba logrando a partir del Primer Plan Quinquenal (1929-1932). Los propagandistas soviéticos proclamaban que habían sido ya prácticamente ganadas las batallas de la industrialización, la colectivización del campo, el aumento de la urbanización, la liquidación del desempleo, la universalización de la educación primaria y la alfabetización de los adultos. Cuando se introdujo la nueva constitución soviética de 1936, Stalin se permitió asegurar que la instalación del

${ }^{48}$ Lozza, Arturo; Brisas y tremolinas. (Episodios en la vida de un hombre de Entre Ríos); Yuquerí; Buenos Aires; 1982; pp. 55-56.

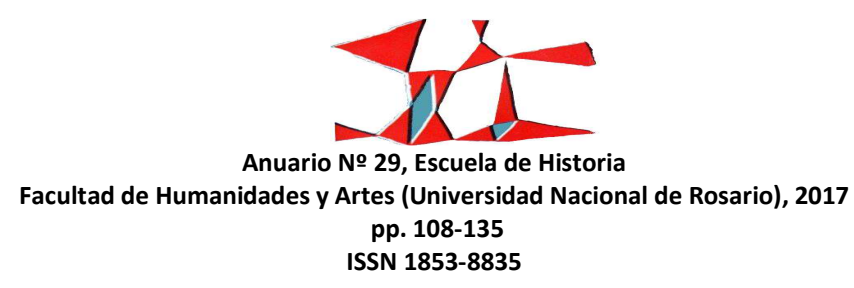




\section{Buenos Aires-Moscú. El partido comunista argentino y la Revolución Rusa hasta los años treinta}

socialismo en la URSS era una misión realizada. La prensa del PC argentino reprodujo en el medio local esta misma visión: el periódico La Internacional y la revista Soviet se convirtieron en propaladores de las extraordinarias novedades sobre los avances de la economía planificada, en tanto que los diarios Bandera Roja y Mundo Obrero contaron con secciones fijas tituladas, respectivamente, "La URSS en construcción" y "Rusia nueva". Allí no se registraban ni los costos humanos de la colectivización forzosa y la industrialización acelerada, ni la multiplicación de los campos de trabajo y detención, ni los inauditos niveles de represión social, política y cultural que había puesto en funcionamiento el régimen de Stalin. Sólo quedaban ilustradas la "exitosa construcción del socialismo" y la emergencia del "nuevo hombre soviético".

\section{Bibliografía Citada}

Acha, Omar; "La revolución rusa de José Ingenieros: elitismo y progresismo"; Herramienta; n²0, año VII; Buenos Aires; invierno de 2002; pp. 163-182.

Agosti, Héctor P.; José Ingenieros, ciudadano de la juventud; Futuro; Buenos Aires; 1945.

Artundo, Patricia; "Entre 'La aventura y el orden'. Los hermanos Borges y el ultraísmo argentino"; en Cuadernos de Recienvenido, $n^{\circ}$ 10; Universidade de São Paulo; São Paulo; 1999; p. 66.

Bayer, Osvaldo; Los anarquistas expropiadores, Simón Radowitzky y otros ensayos; Galerna; Buenos Aires; 1975.

Bergel, Martín; "Un caso de orientalismo invertido. La Revista de Oriente (1925-1926) y los modelos de relevo de la civilización occidental"; Prismas. Revista de historia intelectual; n²10; Bernal; 2006; pp. 99-117.

Bilsky; Edgardo J.; "Etnicidad y clase obrera: la presencia judía en el movimiento obrero argentino"; Estudios Migratorios Latinoamericanos; $n^{\circ} 11$, abril 1989; pp. 27-47.

Borges, Jorge Luis; Autobiografía; El Ateneo; Buenos Aires; p. 60.

Caballero, Manuel; La Internacional Comunista y la revolución latinoamericana, 1919-1943; Nueva Sociedad; Caracas; 1987, pp. 77-78.

Camarero, Hernán; A la conquista de la clase obrera. Los comunistas y el mundo del trabajo en la Argentina; 1920-1935; Siglo XXI Editora Iberoamericana; Buenos Aires; 2007.

133

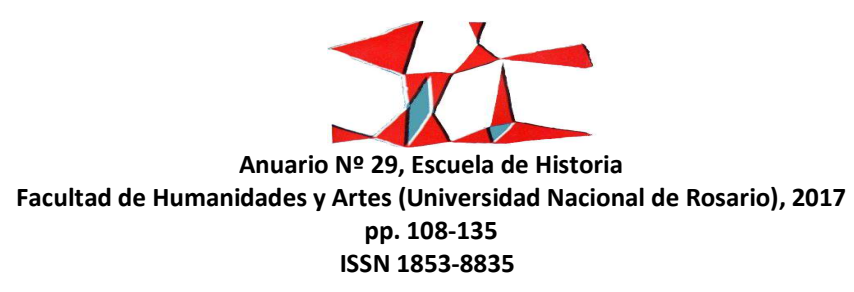


Camarero, Hernán; "Félix Weil y un libro pionero sobre la historia del movimiento obrero y las izquierdas en la Argentina"; The Internacional Newsletter of Communist Studies Online; n² 23; año XVI; Köln; 2010; pp. 6068.

Campione Daniel, López Cantera, Mercedes F. y Maier, Bárbara (comps.); Buenos Aires-Moscú-Buenos Aires: los comunistas argentinos y la Tercera Internacional. Primera parte (1921-1924); Ediciones del CCC Floreal Gorini; Buenos Aires; 2007.

Doeswijk, Andreas; Los anarco-bolcheviques rioplatenses: 1917-1930; Cedinci; Buenos Aires; 2013.

Furet, François; El pasado de una ilusión. Ensayo sobre la idea comunista en el siglo XX; FCE, México; 1995; pp. 76 y 116.

Hobsbawm, Eric; "Problemas de la historia comunista"; en E. Hobsbawm, Revolucionarios. Ensayos contemporáneos; Crítica; Barcelona; 2000; p. 13.

Hobsbawm, Eric; Historia del siglo XX, 1914-1991; Crítica; Barcelona; 1995; p. 63.

Jeifets, Víctor L. y Jeifets, Lazar S; El Partido Comunista de Argentina y la III Internacional. La misión de Williams y los orígenes del penelonismo; Nostromo Ediciones; México; 2013.

Jeifets, Víctor L. y Jeifets, Lazar S.; "La Internacional Comunista y la izquierda argentina primeros encuentros y desencuentros"; en Archivos de historia del movimiento obrero y la izquierda; año III, $\mathrm{n}^{\circ}$ 5, septiembre; Buenos Aires; 2014; pp. 71-92.

Katz, Pinie; Páginas selectas; ICUF; Buenos Aires; 1980.

Kersffeld, Daniel; Rusos y Rojos: judíos comunistas en los tiempos de la Comintern; Capital Intelectual; Buenos Aires; 2012.

Kohan, Néstor; De Ingenieros al Che. Ensayos sobre el marxismo argentino y latinoamericano; Biblos; Buenos Aires; 2000.

Laubstein, Israel; Bund. Historia del movimiento obrero judío; Acervo Cultural; Buenos Aires; 1997.

Lazar S. Jeifets y Víctor L. Jeifets; América Latina en la Internacional Comunista, 1919-1943. Diccionario Biográfico; Ariadna Ediciones; Santiago de Chile; 2015.

Lewin, Boleslao; Cómo fue la inmigración judía en la Argentina; Plus Ultra; Buenos Aires; 1983; pp 173-206.

Lvovich, Daniel; Nacionalismo y antisemitismo en la Argentina; Vergara; Buenos Aires; 2003.

Lozza, Arturo; Brisas y tremolinas. (Episodios en la vida de un hombre de Entre Ríos); Yuquerí; Buenos Aires; 1982; pp. 55-56.

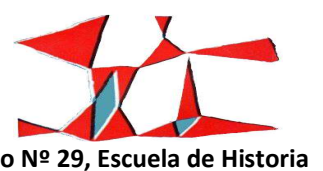

Facultad de Humanidades y Artes (Universidad Nacional de Rosario), 2017

$$
\text { pp. 108-135 }
$$

ISSN 1853-8835 
Meneses, Carlos; Borges en Mallorca (1919-1921); Aitana; Alicante; 1996.

Nolte, Ernst; Después del comunismo; Ariel; Barcelona; 199; p. 41.

Pittaluga, Roberto; Soviets en Buenos Aires. La izquierda de la Argentina ante la revolución en Rusia; Prometeo; Buenos Aires; 2015.

Sarlo, Beatriz; Una modernidad periférica: Buenos Aires 1920 y 1930; Nueva Visión; Buenos Aires; 1988; p. 123-124

Terán, Oscar; "Aníbal Ponce o el marxismo sin nación", En busca de la ideología argentina; Catálogos; Buenos Aires; 1986; p. 159.

Terán, Oscar; José Ingenieros: Antiimperialismo y nación en la Argentina; Siglo XXI, México; 1979.

Tiempo, César; Poesías Completas; Stilman Editores; Buenos Aires; 1979.

Recibido: 4 de mayo de 2017

Aceptado: 27 de julio de 2017

Versión Final: 18 de septiembre de 2017

135

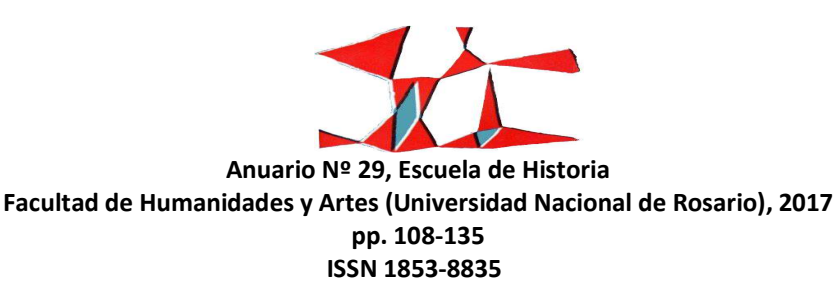

